\title{
EDITORIAL
}

\section{Patient Safety is the Priority for Quality Health Care}

\section{SAFROZA}

Patient safety is the absence of preventable harm to a patient during the process of health care and reduction of risk of unnecessary harm associated with health care to an acceptable minimum. An acceptable minimum refers to the collective notions of given current knowledge, resources available and the context in which care was delivered weighed against the risk of non-treatment or other treatment. ${ }^{1}$

More than 100 (134) million adverse events occur each year due to unsafe care in hospitals in low- and middleincome countries, contributing to 2.6 million deaths annually. $\$ 42$ billion medication errors cost an estimated 42 billion USD annually. ${ }^{1}$ Four out of 10 patients are harmed in the primary and ambulatory settings; up to $80 \%$ of harm in these settings can be avoided. ${ }^{1}$

Many view quality health care as the overarching umbrella under which patient safety resides. ${ }^{2}$ The Institute of Medicine (IOM) considers patient safety as "indistinguishable from the delivery of quality health care." 3

A definition for patient safety has emerged from the health care quality movement that is equally abstract, with various approaches to the more concrete essential components. Patient safety was defined by the Institute of Medicine (IOM) as "the prevention of harm to patients." ${ }^{3}$ Emphasis was given on the system of health care delivery that (1) prevents errors; (2) learns from the errors that do occur; and (3) is built on a culture of safety that involves health care professionals, organizations, and patients. ${ }^{3,4}$

In a recent research done by Humyun and others it reveals that inadequate number of primary level medical officers (44.9\%) understand patients safety and 51.1\% understand medical errors. A few of them (37.5\%) agreed that less duty hours will reduce medical errors and $62 \%$ strongly agreed that learning about patient safety will enhance competency. Some of the participants (40.6\%) stated that they were assigned to perform the tasks for which they were not trained competently, $34 \%$ said that they were assigned to perform the tasks which could have resulted easily in medical errors, $46 \%$ confessed that they made medical errors during their practices. Majority (76.9\%) strongly agreed that patient safety is an important issue in their professional practices. The study recommended that doctors serving at primary and secondary level healthcare facilities should be oriented/ trained on different aspects of patient safety .

In the United States, the full magnitude and impact of errors in health care was not appreciated until the 1990s, when several reports brought attention to this issue. ${ }^{5}$ In 1999, the Institute of Medicine (IOM) of the National Academy of Sciences released a report, To Err is Human: Building a Safer Health System. ${ }^{6}$ The IOM called for a broad national effort to include establishment of a Center for Patient Safety, expanded reporting of adverse events, development of safety programs in health care organizations, and attention by regulators, health care purchasers, and professional societies.

Millennia ago, Hippocrates recognized the potential for injuries that arise from the well-intentioned actions of healers. Greek healers in the 4th century BC drafted the Hippocratic Oath and pledged to "prescribe regimens for the good of my patients according to my ability and my judgment and never do harm to anyone." 7

The global need for quality of care and patient safety was first discussed during the World Health Assembly in 2002, and resolution WHA55.18 on 'Quality of care: patient safety' at the Fifty-fifth World Health Assembly urged Member States to "pay the closest possible attention to the problem of patient safety". Since then, there have been several international initiatives, which have brought the importance of the matter to the attention of policy-makers in many countries. ${ }^{8}$ Those initiatives include

- Development of global norms and standards;

- Promotion of evidenced-based policies;

- Promotion of mechanisms to recognize excellence in patient safety internationally; 
- Encouragement of research;

- Provision of assistance to countries in several key areas.

There are huge number of literatures on patient safety emphasizing the quality health care services. So, as a health professional we should give utmost priority to patient safety before approaching a patient for diagnosis, treatment as well as rehabilitation.

(J Bangladesh Coll Phys Surg 2020; 38: ) DOI: http://dx.doi.org/10.3329/jbcps.v38i1.44681

\section{Prof. Syeda Afroza}

Prof. \& Head, Dept. of Paediatrics, MH Samorita Hospital \& Medical College, Dhaka.

\section{References:}

1. WHO, Patient Safety: https://www.who.int/ patient safety/ en (Accessed on 12.12.2019).
2. Mitchell PH. Defining Patient Safety and Quality Care. In: Hughes RG (Editor). Patient Safety and Quality: An Evidence-Based Handbook for Nurses. Rockville (MD): Agency for Healthcare Research and Quality (US); 2008.

3. Aspden P, Corrigan J, Wolcott J, et al., editors. Patient safety: achieving a new standard for care. Washington, DC: National Academies Press; 2004.

4. Clancy CM, Farquhar MB, Sharp BA. Patient safety in nursing practice. J Nurs Care Qual. 2005;20(3):193-7.

5. Brennan TA, Leape LL, Laird NM. Incidence of adverse events and negligence in hospitalized patients. Results of the Harvard Medical Practice Study I. N. Engl. J. Med. 1991324 (6): 370-6.

6. Institute of Medicine (US) Committee on Quality of Health Care in America, Kohn LT, Corrigan JM, Donaldson MS (eds.). To Err is Human-Building a Safer Health System. 2000; Washington, D. C. National Academies Press. p. 312. doi: $10.17226 / 9728$

7. National Institute of Health, History of Medicine: Greek Medicine Archived 2018-03-07 at the Wayback Machine

8. WHO , Patient Safety: https://www.who.int/patientsafety/ policies/en/(Accessed on 14.12.2019). 